\title{
SIMULATION OF PARTIAL ANAEROBIOSIS IN A MODEL SOIL IN RESPECT TO DENITRIFICATION
}

\author{
P. A. LEFFELAAR \\ Department of Theoretical Production Ecology, Bornsesteeg 65, Wageningen, The Netherlands
}

Received for publication November 10, 1978; revised February 13, 1979

ABSTRACT

Factors affecting anaerobiosis in soil have been studied by means of computer simulation applied to a model soil composed of spherical aggregates in a hexagonal packing. This schematized geometry implies that two different types of pores are distinguished: intra- and interaggregate pores. The moisture characteristics for the interaggregate water and the non-water-covered area of the aggregates, the so-called air-exposed area, were calculated in general terms. The results give a tool to derive curves for a certain aggregate radius. The interaggregate water content is used to calculate the diffusion properties of the model soil down the profile. The diffusion from interaggregate pores into the aggregates is taken proportional to the air-exposed area of the aggregates.

Results of the model are given for an aggregate radius of 0.5 centimeters. They indicate anaerobiosis to occur below a depth of 10 centimeters and in the profile as a whole, before and during rainfall, respectively. The anaerobic soil volume rapidly responds to a shower of rain. However, it is not affected as seriously by the water regime as it is by the magnitude and distribution of the respiratory activity or the diffusion coefficient in the aggregates. The model soil was also used to derive, for a particular case, a soil anaerobiosis characteristic relating soil moisture suction to the anaerobic soil fraction. Some indications are given for further experimental research.

\section{INTRODUCTION}

Oxygen deficiency is a prerequisite for the occurrence of denitrification in soil. ${ }^{1}$ However, denitrification has been reported to occur in well-aerated soils too (Broadbent 1951). This suggests the existence of anaerobic locations in soils normally considered well-aerated. Such anaerobic pockets could be due to the presence of structural elements in the soil. Currie (1961) states that soil microorganisms and plant roots require intimate contact with the soil particles for satisfactory uptake of nutrients and water and, therefore, are predominantly found in the finer pores of the soil. Consequently, respiration tends to take place within the aggregates rather than between them. Centers of aggregates thus may become anaerobic, introducing spatial differences in oxygen status. This variability is a major problem in interpreting soil aeration mea-

${ }^{1} \mathrm{~J} . \mathrm{W}$. Woldendorp, 1963, The influence of living plants on denitrification, Ph.D. thesis, Wageningen, The Netherlands. surements (Flühler et al. 1976). These authors therefore consider the approach of Currie (1961) and Greenwood (1961), who described the aeration status within spherical soil aggregates, as a key for eliminating existing misinterpretations of soil aeration measurements.

Some attempts to model anaerobiosis are reported by van Veen (1977) ${ }^{2}$ and Smith (1977). The former regarded the soil as a bundle of capillaries, whereas the latter considered spherical aggregates having a certain size distribution but did not take into account their spatial arrangement.

The subject of this study is the dynamic behavior of the anaerobic soil fraction in a model soil, consisting of spherical aggregates, by a computer simulation technique. Evaluation of the model may lead to increased insight into the relative importance of the variables incorporated. Results thus obtained can be used to

${ }^{2}$ H. van Veen, 1977 , The behavior of nitrogen in soil-a simulation study, Ph.D. thesis, Vrije University, Amsterdam. 
indicate subjects that should be investigated experimentally.

\section{DESCRIPTION OF THE MODEL SOIL}

\section{Basic considerations}

Many soil types show structural units, in the centers of which anaerobiosis may be found. The oxygen status of a particular aggregate in a soil is governed by its dimensions, the oxygen concentration at the outside, the oxygen consumption rate, and the diffusion coefficient in the interior. The latter is largely determined by the water content and the solubility of oxygen in water. The oxygen concentration at the outside is governed by the macrodiffusion process of oxygen from the atmosphere into the soil, which mainly takes place through the interaggregate pores. Because the diffusion coefficient of oxygen is about $10^{4}$ times smaller in water than in air, the diffusion rate of oxygen from an interaggregate pore into an aggregate is reduced when water partially covers the aggregate, as may occur at contact points. Thus the moisture characteristics of a soil are important in determining its oxygen status. These considerations have resulted in a model soil consisting of spherical aggregates in a hexagonal packing, enabling us to perform calculations concerning interaggregate moisture content and oxygen transport in aggregated soils.

\section{Geometry}

The model soil is composed of spherical aggregates of three sizes. The largest aggregates are arranged in a hexagonal packing, and the smaller aggregates fit exactly in the tetrahedral and octahedral voids of this packing. A unit hexagonal packing contains 6,12 , and 6 equidimensional, tetrahedral, and octahedral spheres, respectively. Their radii are in the proportion of

$$
\begin{aligned}
R: R_{4}: R_{8} & =R: R \frac{2}{3}^{1 / 2}\left(\frac{3}{2}-\frac{3}{2}^{1 / 2}\right): R\left(2^{1 / 2}-1\right) \\
& =1: 0.2247: 0.4142
\end{aligned}
$$

The total height of such a unit is $2 / 3^{1 / 2} \times 4 R$, and it has a volume of $2^{1 / 2} \times 24 R^{3}$. It has a porosity of 19.0083 percent with and 25.952 percent without inscribed spheres. A detailed description of the model soil is given by Leffelaar (1977). Slichter (1899) and Azároff (1960) give extensive descriptions of the equidimensional sphere packing without inscribed spheres.

\section{Physical characteristics of the model soil}

\section{Volume of the pendular water ring}

In the model soil the water in the interaggregate pores is present in the form of annuli of wedge-shaped cross section around the points of contact of the aggregates (pendular rings). The volume of water held at given suctions may be calculated for equidimensional aggregates (Wilsdon 1921). However, the model soil contains aggregates of different sizes, which requires a more general formula for unequal spheres. This formula was derived using the coordinate system of Fig. 1.

The volume of the pendular water ring $V_{p r}$ may be calculated as the difference between the volumes of a truncated cone $V_{c}$ and the two spherical segments $V_{R}$ and $V_{R_{x}}$ and the fraction of a torus $V_{t}$ included by the cone, Eq. (1).

$$
V_{p r}=V_{c}-\left(V_{R}+V_{R_{x}}+V_{t}\right)
$$

where

$$
\begin{aligned}
V_{c}= & \frac{\pi}{3}\left\{R_{x}(1-\cos \alpha)\right. \\
& +R(1+\cos (\alpha+\beta))\} \\
& \cdot\left\{R^{2} \sin ^{2}(\alpha+\beta)+R_{x}{ }^{2} \sin ^{2} \alpha\right. \\
& \left.+R_{x} \sin \alpha R \sin (\alpha+\beta)\right\} \\
V_{R}= & \frac{\pi}{12} R^{3}\{8+9 \cos (\alpha+\beta) \\
& -\cos 3(\alpha+\beta)\} \\
V_{R_{x}}= & \frac{\pi}{12} R_{x}^{3}\{8-9 \cos \alpha+\cos 3 \alpha\} \\
V_{t}= & \pi\left\{r^{2} \sin \alpha\left(r+R_{x}\right)\left(\frac{2 \pi \beta}{360}-\sin ^{3} \beta\right)\right. \\
& \left.-\frac{4}{3} r^{3} \cos \left(\alpha+\frac{1}{2} \beta-90\right) \sin ^{3} \frac{1}{2} \beta\right\}
\end{aligned}
$$

A number of assumptions were made to develop Eqs. (1) to (5): (1) gravitational distortion was ignored; (2) the properties of the solid-fluid interface were assumed to be uniform with a contact angle of zero degrees, as made plausible 


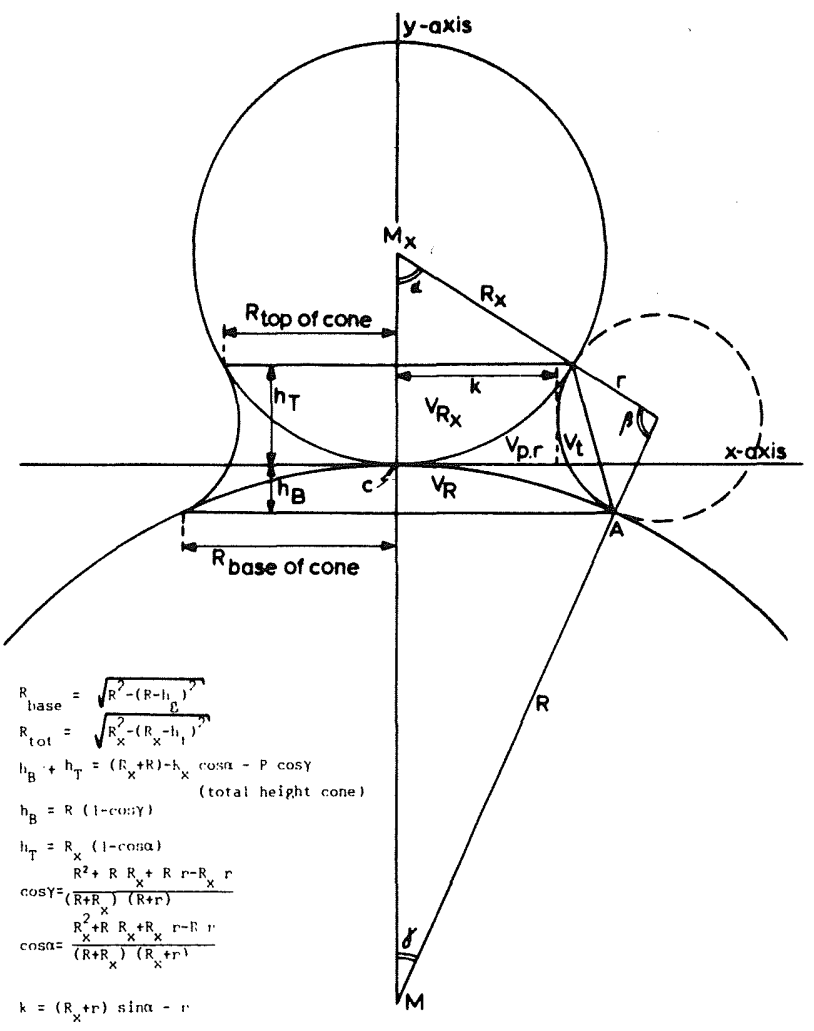

FIG. 1. General coordinate system to calculate pendular ring volume.

by Kruyer (1958); (3) the surface free energy of the air-water interface is supposed to be equal in each point. Though this condition is not met in the case of a toroidal surface, comparison with exact data presented by Kruyer (1958) for an equidimensional system showed this approximation to introduce a maximum positive absolute and relative error in the volumetric moisture content of 0.21 percent and 3.39 percent, respectively. Numerical results obtained with Eqs. (1) to (5) were favorably compared with Wilsdon's (1921) formula for equidimensional spheres $(\alpha=\gamma)$.

Relationship between suction and pendular water volume

The relation between matric suction $S m$ and surface tension $\sigma$ may be described by

$$
S m=\frac{\sigma}{\rho g}\left(\frac{1}{r_{1}}+\frac{1}{r_{2}}\right)
$$

The radii of the pendular water rings are of opposite sign and are given by $r_{1}=r$ and $r_{2}$

$$
\left\{\left(R_{x}-r\right) \frac{2\left\{\left(R+R_{x}+r\right) R R_{x} r\right\}^{1 / 2}}{R_{x}\left(R+R_{x}+r\right)+R r}-r\right\}
$$

At a given suction the radii of curvature belonging to equal and unequal spheres are different. Therefore, the radii were calculated for appropriate suction values and were subsequently used to calculate the corresponding water volumes. The volumetric moisture content $\theta_{v}(\%)$ for a hexagonal packing was obtained by Eq. (8)

$$
\theta_{v}(\%)=\frac{36 V_{p r}+48 V_{p r 4}+36 V_{p r 8}}{2^{1 / 2} \times 24 R^{3}} \times 100
$$

The relation between volumetric water content and suction for the model soil, containing nonporous aggregates, may now be calculated using Eqs. (1) to (8). The result is presented in Fig. 2 in terms of the dimensionless quantities Sm $R \rho g / \sigma$ and $\theta_{v}$. Taking a value of $13.4 \mathrm{~cm}^{-2}$ for $\rho g / \sigma$ and $0.5 \mathrm{~cm}$ for $R$, which radius is assumed to be a fair estimate for the largest aggregates in a well-prepared seed bed, the suction 


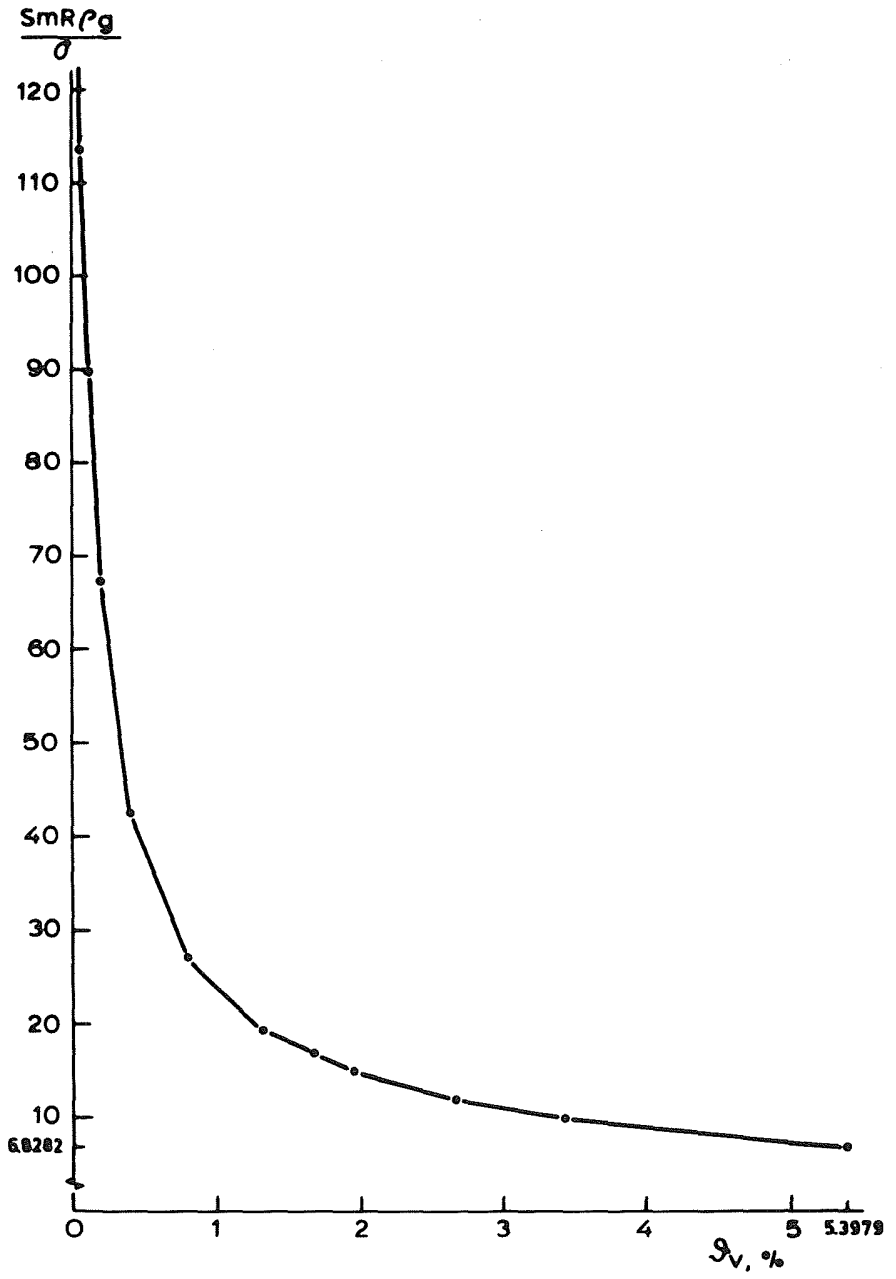

Fig. 2. Moisture characteristic of hexagonal.

can be calculated as $2.18 \mathrm{~cm} \mathrm{H}_{2} \mathrm{O}$ when $\theta_{v}=2$ percent. The low maximum moisture content of 5.3979 percent results from the fact that, at still higher moisture contents, neighboring water rings coalesce, and Eqs. (1) to (8) no longer hold (Haines 1927; Keen 1924). The angle $\gamma$ at which this process starts amounts to $30,16.79$, and $13.27^{\circ}$ for $R-R, R-R_{8}$, and $R-R_{4}$ spheres, respectively.

It should be pointed out that the hexagonal closest sphere packing is not isotropic; ${ }^{3}$ each sphere has a different number of water rings. This complication was not considered; instead

${ }^{3} \mathrm{~J}$. van Brakel, 1975, Capillary liquid transport in porous media, Ph.D. thesis, University of Technology, Delft, Pasmans, 's-Gravenhage. an average number of different rings per sphere was calculated.

The model soil aggregates were next assigned a porosity according to the soil properties of a sandy loam soil (Stroosnijder 1976, p. 87), resulting in a total porosity of 65.51 percent. The hydraulic properties of the complete model soil were obtained by simply adding the two moisture characteristics. Thus, the moisture characteristic of the sandy loam uniquely refers to the intraaggregate pores. This procedure could be repeated for other soil types to provide information on the relative importance of moisture depletion within the aggregates at different suctions on anoxity. It is not intended to simulate the hydraulic properties of a sandy loam soil. However, the procedure indicates the need of 
quantitative knowledge of how different pore types drain and moisten when suction is changed (Stolzy and Flühler 1978).

\section{Air-exposed area of aggregates}

Diffusion of oxygen from interaggregate pores into the aggregates, is taken proportional to the air-exposed area of the aggregates. This area is complementary to the area covered by the pendular water rings and can be calculated by Eq. (9)

$$
\begin{aligned}
& \operatorname{AEA}(\%)= \\
& \left\{1-\frac{C}{2}\left(1-\frac{R_{x}\left(R_{x}+R\right)+r\left(R_{x}-R\right)}{\left(R_{x}+R\right)\left(R_{x}+r\right)}\right)\right\} \times 100
\end{aligned}
$$

The relation between moisture content $\theta_{v}$ and air exposed area AEA is shown in Fig. 3. We explain below how this parameter is applied in the calculations.

The ratio $\mathrm{D} / \mathrm{D}_{0}$ pertaining to the oxygen macrodiffusion process

Millington and Shearer (1971) advanced an equation to calculate the ratio of the diffusion coefficient of molecules $D$ in a porous system having intra- and interaggregate pores, to the diffusion coefficient in the same medium (water or air) without any solid obstacles $D_{0}$. Their equation was used to describe the oxygen diffusion process in the model soil, the result being shown in Fig. 4. Obviously, the ratio $D / D_{0}$ is much less affected by filling of intraaggregate pores than by filling of interaggregate pores. The ratio $D / D_{0}$ thus calculated $\left(0.04<D / D_{0}<0.18\right)$ is in the expected order of magnitude when compared to data from Currie (1965): $0.025<$

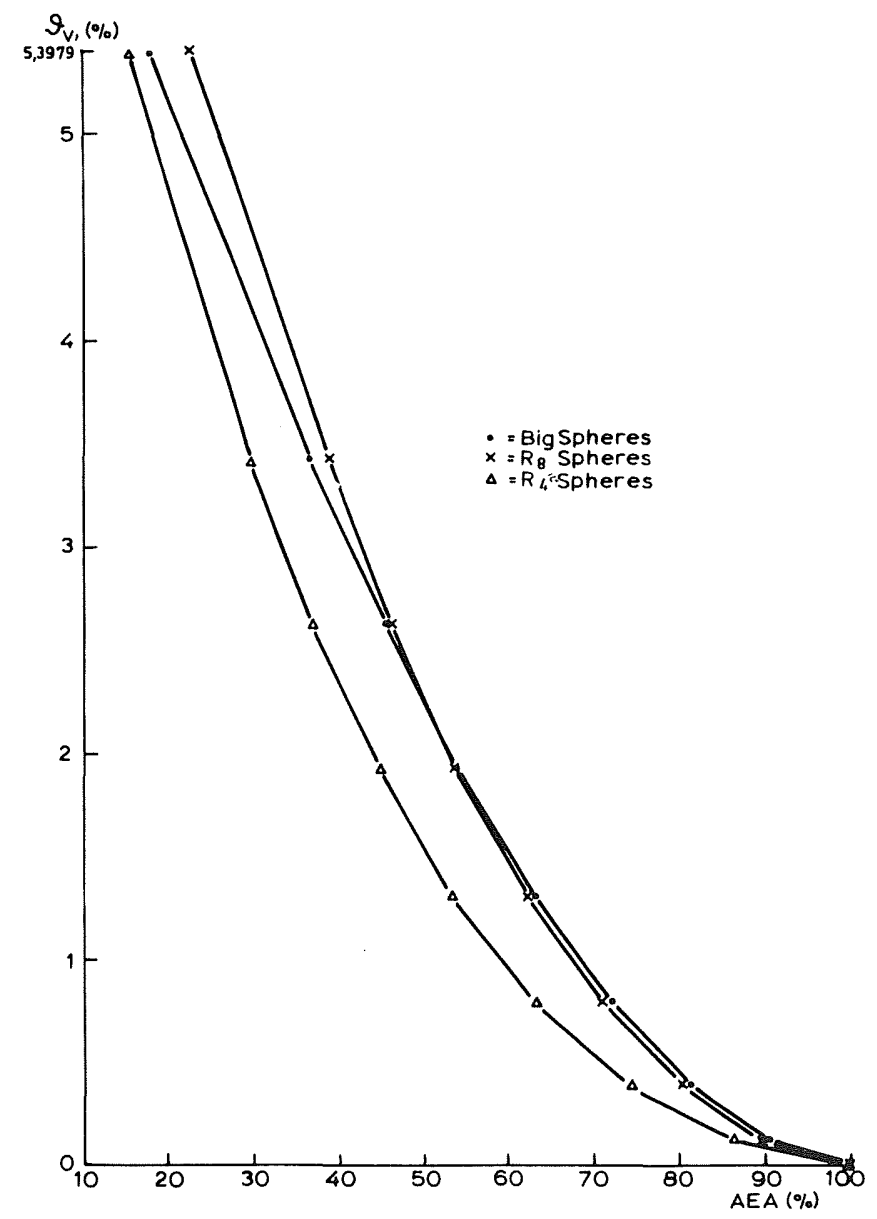

FIG. 3. The relation between air-exposed area of spheres and moisture content. 


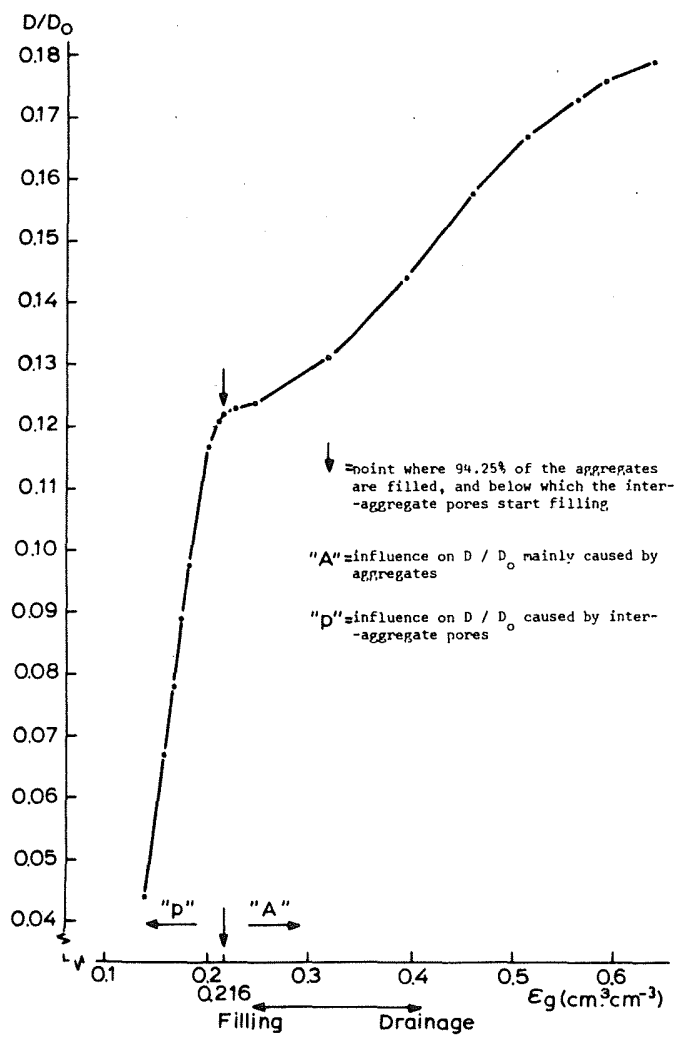

Fig. 4. The relation between $D / D_{0}$ and gas-filled porosity $\epsilon_{g}$.

$D / D_{0}<0.156$, measured for eight soils with aggregate porosities in the range of 25 to 41 percent.

\section{Diffusion within an aggregate}

Oxygen diffusion within the aggregates is described by an analytical solution to the diffusion equation (Currie 1961), assuming steady-state conditions. This assumption is supported by Radford and Greenwood (1970), who found simulated concentrations of oxygen to reach at least 95 percent of their equilibrium values within 3 $\min$.

Diffusion coefficients pertaining to the waterfilled part of the aggregates were calculated according to Millington and Shearer (1971), multiplied by the air-exposed area (AEA) of the appropriate aggregate size, and used in the diffusion equation.

The distribution of the respiratory activity over the aggregates will be discussed in the section about the computer model.
The maximum radius at which an aggregate is still fully aerobic, called critical radius, is strongly dependent on moisture content. Therefore, the water distribution within the aggregates should be known. As a first approximation it was supposed to be accumulated in a concentric sphere. The equivalent radii of such water spheres, was calculated by Eq. (10)

$$
r_{\mathrm{eq}}=R\left(\frac{\theta_{v}}{\epsilon}\right)^{1 / 3}
$$

The ratio of the equivalent and critical radii was converted to the anaerobic aggregate volume as described by Currie (1961, Eq. (16)).

\section{Hydraulic conductivity}

The hydraulic conductivity of the model soil was calculated by the procedure of Green and Corey (1971) on the basis of the soil moisture characteristic given by Stroosnijder (1976). The moisture characteristic was divided into 20 classes of $\Delta \theta_{v}=0.0135$ each, ranging from $\theta_{v}=$ 0.465 to 0.195 or from $\mathrm{Sm}=0.0$ to $-200 \mathrm{~cm} \mathrm{H}_{2} \mathrm{O}$. Beyond this value the moisture transport was assumed to be negligible. The curve was matched with the measured hydraulic conductivity, amounting to $16.5 \mathrm{~cm} \mathrm{day}^{-1}$ (Stroosnijder, 1976), and it was linearly extrapolated to account for higher suction values. The results of the calculations are shown in Fig. 5.

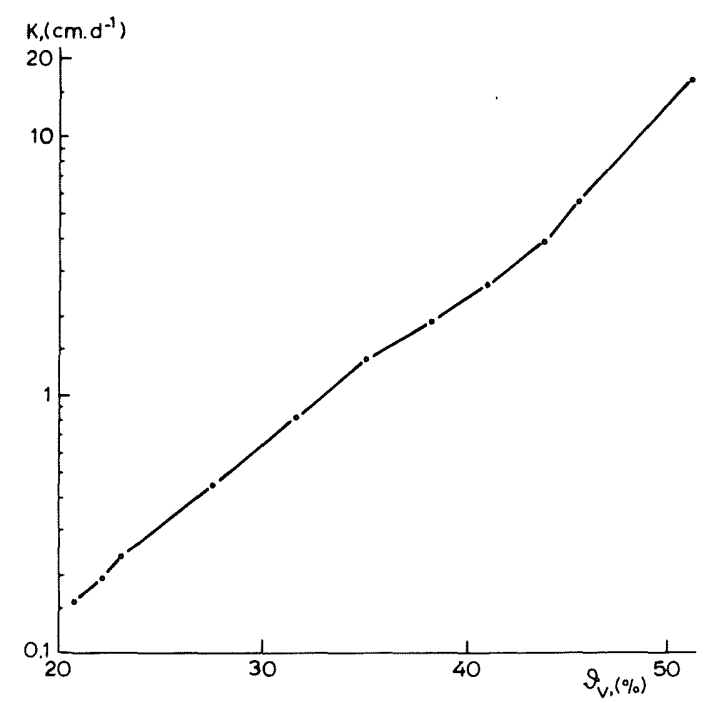

FIG. 5. The relation between hydraulic conductivity and moisture content. 
THE COMPUTER MODEL

The computer model was written in CSMPIII and executed on a DEC 10 machine. Basic principles of the language are discussed by de Wit and Goudriaan (1978) and de Wit and van Keulen (1975). The latter report deals especially with transport processes in soils. The computer program will not be discussed in detail, but additional assumptions used to develop the program are enumerated.

The soil considered is made up of 15 layers, each having a thickness of a unit hexagonal sphere packing. The radius of the largest aggregates was taken as $0.5 \mathrm{~cm}$, resulting in a total soil depth of $24.495 \mathrm{~cm}$. The upper layer is exposed to air.

The main cause of oxygen transport through the soil is molecular diffusion. However, mass flow of oxygen takes place complementary to the mass flow of water. This process is also taken into account.

The oxygen consumption rate, including both root and microbial respiratory activity, and the rate of moisture extraction by the roots are distributed homogeneously over the aggregates in the rooted profile and are proportional to the aggregate volumes, as long as no anaerobiosis occurs. However, when anaerobic microsites develop, these rates are reduced in proportion to the anaerobic aggregate fraction. The oxygenconsumption rate is taken as constant down to a critical oxygen concentration denoting effective anaerobic conditions.

The flow rate of oxygen out of the last compartment is taken as zero, as no oxygen is consumed beyond that depth. For water flow the transport is governed by the average hydraulic conductivity and the matric suction in the last compartment and the depth where the groundwater table is projected. The water flow submodel is based on the model of van Keulen and van Beek (1971). Rain is introduced in the model by means of a block function, with an intensity of $9 \mathrm{~cm} \mathrm{day}^{-1}$ and durations of 3 or $6 \mathrm{~h}$.

\section{Model parameters}

Grable (1966) reported values for oxygen consumption ranging from 5 to 10 liters $\mathrm{O}_{2} \mathrm{~m}^{-2}$ soil surface day ${ }^{-1}$. Bakker and Hidding (1970) reported this value to be about 9 liters for microorganisms only, and Woldendorp ${ }^{1}$ showed that the ratio of respiratory activity of roots to microorganisms was 2 to 1 . From these estimates it is concluded that the lowest and highest oxygen consumption rates would be about 10 and 27 liters $\mathrm{O}_{2} \mathrm{~m}^{-2}$ soil surface $\cdot 25 \mathrm{~cm}_{\text {depth }}{ }^{-1}$ day $^{-1}$.

The diffusion coefficient of oxygen in free water is $2.24 \mathrm{~cm}^{2}$ day $^{-1}$ at $T=25^{\circ} \mathrm{C}, P=1$ bar (Lemon and Wiegand 1962). $D / D_{0}$, calculated according to Millington and Shearer (1971) for a water-filled part of an aggregate with porosity of $0.465 \mathrm{~cm}^{3} \mathrm{~cm}^{-3}$, equals 0.0566 , resulting in $D=0.1272 \mathrm{~cm}^{2}$ day $^{-1}$. The diffusion coefficient of oxygen in free air was reported to be 19,526 $\mathrm{cm}^{2}$ day $^{-1}$. The relative solubility of oxygen in water at $25^{\circ} \mathrm{C}$ is $2.98 \times 10^{-2}$ (Grable 1966).

The critical oxygen concentration was taken as $2.24 \times 10^{-8} \mathrm{~g} \mathrm{O}_{2} \mathrm{~cm}^{-3}$ (Greenwood 1961).

\section{MODEL EVALUATION}

Evaluation of the model was performed by studying the relative influence of changes in input data on the anaerobic volume fraction (sensitivity analysis). Therefore, results of simulation runs differing in one parameter or function, are compared with a so-called basic run (run no. 1). The schedule of simulation runs is presented in Table 1. Results in terms of the fractional anaerobic volume (FANVOL) plotted against time are shown for some simulation runs in Figs. 6 through 10, for soil layers 1, 7, and 15 corresponding to average depths of $0.8,10.6$, and $23.7 \mathrm{~cm}$, respectively. The parameters tested may be divided in two categories: those directly affecting oxygen status (runs $2,3,4$, and 5), and those indirectly affecting it by governing the water regime of the soil (runs 6, 7, and 8).

At the onset of the simulations, about 0.05 day is needed to adjust FANVOL to its right initial value. This adjustment is particularly clear in Figs. 7 and 8. At that time, Figs. 6 to 10 indicate the presence of anaerobic microsites in the soil layers below $10 \mathrm{~cm}$. So, the soil is a source for continuous denitrification, provided no other limitations prevail. Further, these figures show a rain of $11.25 \mathrm{~mm}$ to affect anaerobiosis for about 1 day.

Figure 7 shows the respiration to have a pronounced effect on anaerobiosis. Initially in the upper layer an anaerobic soil fraction of about 11 percent is calculated, and the maximum after $3 \mathrm{~h}$ rain $(11.25 \mathrm{~mm})$ is 8.7 times that, in case the consumption rate is a factor of 2.7 lower. The model soil is thus very sensitive to changes in respiratory activity.

Results of run 3 can be visualized by adjusting 
TABLE

Schedule of simulation runs

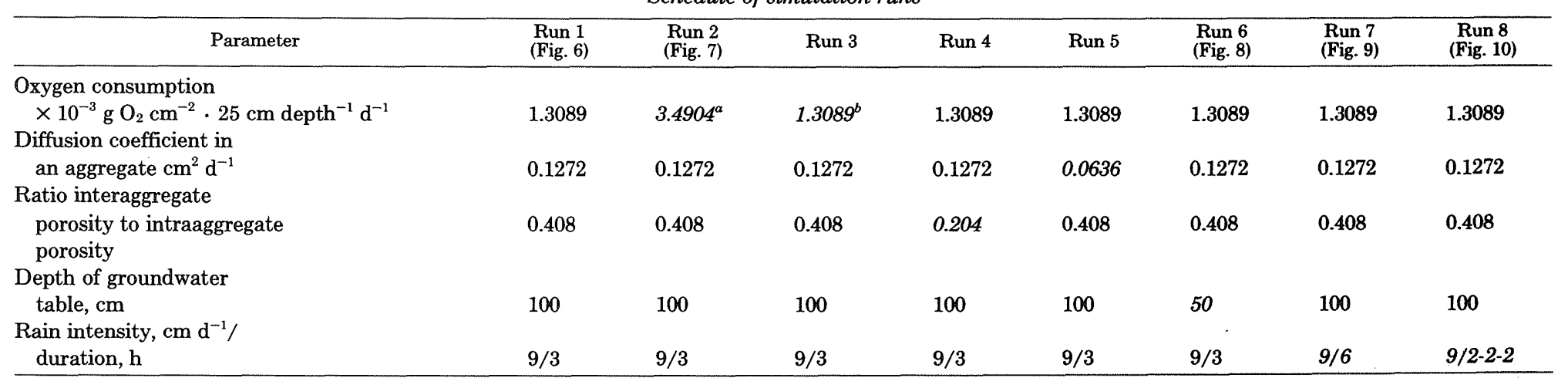

${ }^{a}$ Italic parameters are changed as compared to simulation run 1 .

${ }^{b}$ Half the aggregates respire, while total oxygen consumption rate is the same as in simulation run 1.
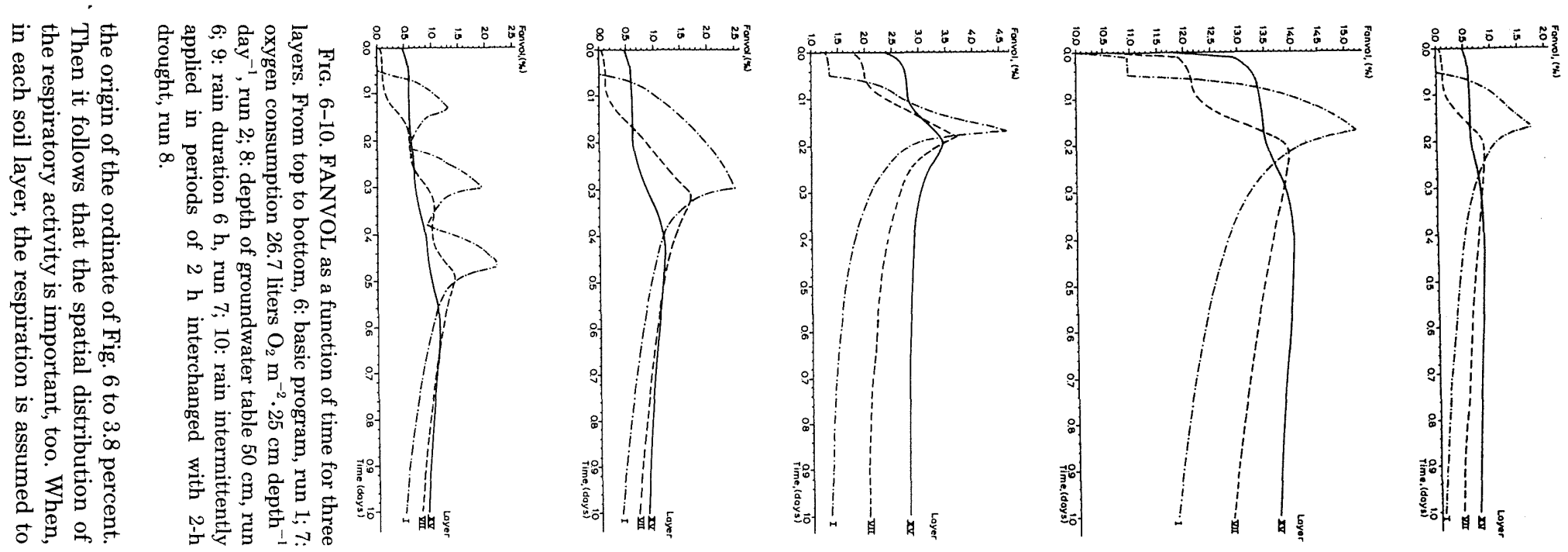
take place in 50 percent of the aggregates, the anoxic volume increases by a factor of 3 for the top layer.

In run 4 the ratio of inter- to intraaggregate pores was decreased from 0.4 to 0.2 , and $D / D_{0}$ was recalculated. Anaerobiosis was somewhat less affected than by halving the diffusion coefficient in the aggregates, run 5 . The latter change was made to simulate the presence of slickensides on aggregates, which are expected to impair oxygen transport. Anaerobiosis in the case of runs 4 and 5 can be visualized by diminishing the values of FANVOL of Fig. 7 by 6.6 and 4.4 percent, respectively.

From the results presented it may be concluded that the model is very sensitive to parameters directly affecting oxygen status; the change in FANVOL in all cases was greater than the twofold change in the value of a particular parameter. Further experimental work is needed, however, to test whether the calculated anaerobic volumes do occur in reality. Some evidence that mathematical equations, very similar to the ones used in this study, hold for saturated soil aggregates was reported by Greenwood and Goodman (1967).

Figure 8 demonstrates the influence of depth of the groundwater table on anaerobiosis, which in this case was $50 \mathrm{~cm}$ below the soil surface instead of $100 \mathrm{~cm}$. FANVOL increases more than proportionally with the ratio of the water table depths. This implies that in most of the Dutch grassland area, where shallow water table depths prevail during the greater part of the year, anaerobic conditions could easily occur.

Rain duration (Fig. 9) and distribution (Fig. 10) have a minor impact on soil anaerobiosis. It is remarked, however, that no very extreme circumstances were simulated, e.g., the minimum gas-filled pore fraction was $0.23 \mathrm{~cm}^{3} \mathrm{~cm}^{-3}$ in run 7. Comparing this value with Fig. 4 , we learn that it is on the safe side: $D / D_{0}$ is still large. This is also the reason that pendular water rings did not seriously affect the anaerobic soil volume. The difference between the influence of normal water regimes and parameters directly affecting soil anaerobiosis may also be demonstrated by the ratio of the average FANVOL for the whole soil profile in the different simulation runs, to that in the basic run. For runs 7 and 8 this ratio is about 1.1 , for run 6 it is about 1.3 , and for runs $2,3,4$, and 5 it is about 3.4. These values stress the importance of experiments to determine the parameters that directly affect the oxygen status of the soil.

The value of the critical oxygen concentration hardly affected anaerobiosis, even when it was set 10 times higher. This was also true for the rate of water extraction (transpiration), normally $0.3 \mathrm{~cm} \mathrm{day}^{-1}$, when tripled to 0.9 . Therefore no separate figures are presented.

The instantaneous increase of anaerobiosis in the surface soil after the onset of rain suggests the possibility that denitrification occurs directly, too. This was reported by Burford and Greenland (1970).

Figure 11 shows curves relating the anaerobic soil fraction to suction for three interaggregate oxygen concentrations, e.g., 21,19 , and 17 percent, using the values of the parameters of the basic run (Table 1, first three lines). A soil in which aggregate size does not exceed $1 \mathrm{~cm}$ should hardly suffer from anaerobiosis at suctions above $100 \mathrm{~cm} \mathrm{H}_{2} \mathrm{O}$. The smaller aggregates did not contribute to the anaerobic soil volume. The rapid increase in anaerobic volume with decreasing moisture tension occurs because the degree of water saturation has a strong impact on the diffusion coefficient of oxygen. The curves presented in Fig. 11 might be called "soil anaerobiosis characteristics," analogous to the term "soil moisture characteristic" (Childs 1940).

It was not attempted to use the model for predictive purposes, as experimental data of the anaerobic soil fraction should be obtained first to verify whether the right order of magnitude is being calculated.

\section{DISCUSSION}

The computer model presented probably tends to underestimate occurrence of anaerobiosis. First, rather small principal aggregate sizes have been chosen. Secondly, the total soil porosity is high, facilitating oxygen diffusion, with the result that the lowest interaggregate concentration calculated was 19.9 percent, for the deepest soil layer in run 2. Thirdly, oxygen diffusion may be impaired by incomplete wetting of soil aggregates. Emerson (1955) reported some evidence for this. It was shown that the process of water uptake by soil aggregates was delayed for some time. One can derive from his Fig. 2 that it takes about 6.6 and 17.2 days to absorb 90 and 97.5 percent of the total water uptake by a grassland surface aggregate, respectively. Stroosnijder and Koorevaar (1972) reported that soil air pressure 


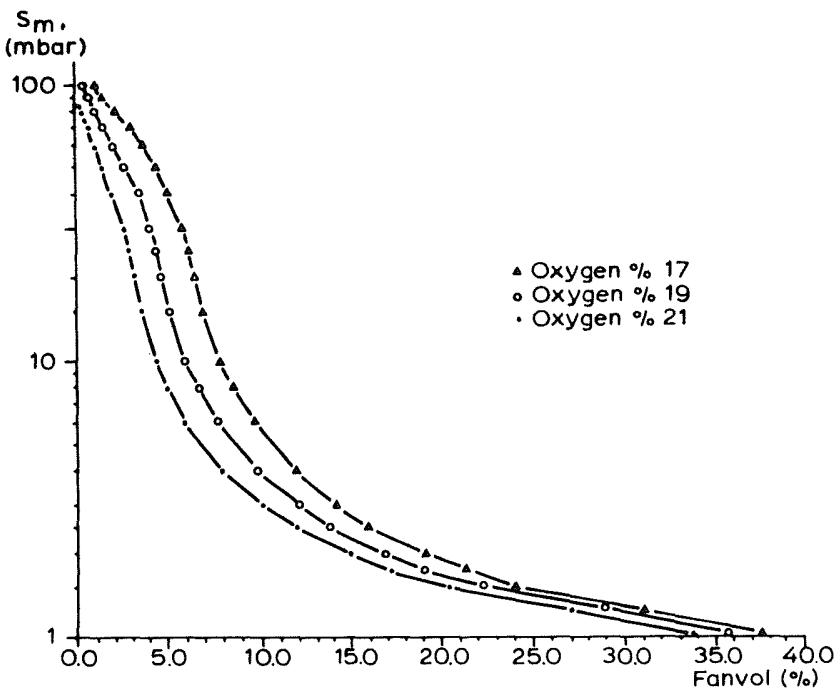

FIG. 11. The relation between suction and FANVOL for three oxygen concentrations for the model soil.

inside the elements increased to values above atmospheric pressures upon the entrance of water into soil aggregates. Based on these findings, one would expect that, after the onset of rain, mainly the outer shell of an aggregate would be directly wetted, possibly resulting in blocking of the pores and impaired oxygen transport. Air is enclosed then, the oxygen is readily consumed, and hence a greater anaerobic soil volume will result than when water is located in the center of the aggregates. Fourth, pool and/or crust formation will also increase anaerobiosis. However, replacing the top soil layer in the simulation model by an empirical equation for crust formation, as reported by Bakker and Hidding (1970), did not confirm that oxygen diffusion was impaired and anaerobiosis enhanced. This result is in accordance with a theoretical analysis by van Bavel (1951).

Conditions that positively influence soil anaerobiosis in the field are the possible presence of soil cracks and soil surface evaporation, which have not been taken into account in the simulation model.

This modeling actively proved to be useful to unite existing knowledge, to discover deficiences in this knowledge, and to estimate the relative importance of the variables used. Future research will, to a large extent, be based on the results presented in this paper. In particular, attention will be paid to the distribution of water and oxygen in individual soil aggregates.

\section{LIST OF SYMBOLS}

$\alpha, \beta, \gamma$ angles expressed as degrees, Fig. 1

$\epsilon$ void fraction of an aggregate, $\mathrm{cm}^{3} \mathrm{~cm}^{-3}$

$\theta_{v}$ volumetric moisture fraction pertaining to the complete soil or to the aggregates (Eq. 10), $\mathrm{cm}^{3} \mathrm{~cm}^{-3}$ or percent

$\rho$ density of water, $\mathrm{g} \mathrm{cm}^{-3}$

$\sigma$ surface tension of water, dynes $\mathrm{cm}^{-1}$

$g$ acceleration due to gravity, $\mathrm{cm} \mathrm{s}^{-2}$

$r_{1}, r_{2}$ radii of curvature of air-water interface of pendular rings, $\mathrm{cm}$

$r_{\mathrm{eq}}$ equivalent radius of water-filled sphere in an aggregate, $\mathrm{cm}$

AEA air-exposed area of an aggregate, percent $C$ number of contact points between aggregates

FANVOL fraction anaerobic volume of soil, $\mathrm{cm}^{3} \mathrm{~cm}^{-3}$ or percent

$R$ radius of a big aggregate, $\mathrm{cm}$

$R_{x}$ when $x=4$, the radius of an inscribed aggregate in a tetrahedral void, and when $x$ $=8$, the same for an octahedral void, $\mathrm{cm}$

$R-R$ the contact between equidimensional aggregates

$R-R_{x}$ the contact between unequal aggregates where $x$ can either be 4 or 8

$V$ volume of water, $\mathrm{cm}^{3}$, Fig. 1

indexes to $V$ :

$c$ truncated cone

pr pendular water ring

prx pendular water ring between an inscribed aggregate $R_{x}$ and a big one 
$R$ refers to a spherical segment of one base of the big aggregates

$R_{x}$ refers to the same of inscribed aggregates

$t$ the fraction of the torus included by the cone

\section{NOTE}

A listing of the computer program that produced these results is available from the author.

\section{ACKNOWLEDGMENTS}

The helpful suggestions of Dr. J. Goudriaan and Dr. H. van Keulen are kindly acknowledged. Assistance in drawing the figures by Mr. G. C. Beekhof and the typing of the manuscript by Mrs. C. G. Uithol is appreciated.

\section{REFERENCES}

Azároff, L. V. 1960. Introduction to solids. McGrawHill, New York.

Bakker, J. W., and A. P. Hidding. 1970. The influence of soil structure and air content on gas diffusion in soils. Neth. J. Agric. Sci. 18: 37-48.

Bavel, C. H. M., van. 1951. A soil aeration theory based on diffusion. Soil Sci. 72: 33-46.

Broadbent, F. E. 1951. Denitrification in some California soils. Soil Sci. 72: 129-137.

Burford, J. R., and D. J. Greenland. 1970. Denitrification under an annual pasture. Proc. XIth Int. Grasslands Congr. Australia, pp. 458-461.

Childs, E. C. 1940. The use of soil moisture characteristics in soil studies. Soil Sci. 50: 239-252.

Currie, J. A. 1961. Gaseous diffusion in the aeration of aggregated soils. Soil Sci. 92: 40-45.

Currie, J. A. 1965. Diffusion within soil micro-structure, a structural parameter for soils. J. Soil Sci. 16: $279-289$.

Emerson, W. W. 1955. The rate of water uptake of soil crumbs at low suctions. J. Soil Sci. 6: 147-159.

Flühler, H., L. H. Stolzy, and M. S. Ardakani. 1976. A statistical approach to define soil aeration in respect to denitrification. Soil Sci. 122: 115-123.

Grable, A. R. 1966. Soil aeration. Adv. Agron. 18: 57106

Green, R. E., and J. C. Corey. 1971. Calculation of hydraulic conductivity: A further evaluation of some predictive methods. Soil Sci. Soc. Am. Proc. 35: 3-7.

Greenwood, D. J. 1961. The effect of oxygen concentration on the decomposition of organic materials in soil. Plant Soil 14: 360-376.

Greenwood, D. J., and D. Goodman. 1967. Direct measurements of the distribution of oxygen in soil aggregates and in columns of fine soil crumbs. J. Soil Sci. 18: 182-196.

Haines, W. B. 1927. Studies in the physical properties of soils: 4. A further contribution to the theory of capillary phenomena in soil. J. Agric. Sci. 27: 264290.

Keen, B. A. 1924. On the moisture relationships in an ideal soil. J. Agric. Sci. 14: 170-177.

Keulen, H., van, and C. G. E. M. van Beek. 1971. Water movement in layered soils. Neth. J. Agric. Sci. 19: 138-153.

Kruyer, S. 1958. The penetration of mercury and capillary condensation in packed spheres. Trans. Faraday Soc. 54: 1758-1767.

Leffelaar, P. A. 1977. A theoretical approach to calculate the anaerobic volume fraction in aerated soil in view of denitrification. A computer simulation study. Report no. 9, Dept. of Theoretical Production Ecology, Agricultural University, Wageningen, The Netherlands (available on request).

Lemon, E. R., and C. L. Wiegand, 1962. Soil aeration and plant root relations: 2. Root respiration. Agron. J. 54: 171-175.

Millington, R. J., and R. C. Shearer. 1971. Diffusion in aggregated porous media. Soil Sci. 111: 372-378.

Radford, P. J., and D. J. Greenwood. 1970. The simulation of gaseous diffusion in soils. J. Soil Sci. 21: 304-313.

Slichter, C. S. 1899. Theoretical investigation of the motion of ground waters. 19th Annual report U.S. Geol. Survey, part II, pp. 295-328.

Smith, K. A. 1977. Soil aeration. Soil Sci. 123: 284-291.

Stolzy, L. H., and H. Flühler. 1978. Measurement and prediction of anaerobiosis in soils. In Nitrogen in the environment, vol. 1. D. R. Nielsen and J. G. McDonald (eds.). Academic, New York, pp. 363426.

Stroosnijder, L. 1976. Infiltratie en herverdeling van water in grond. Pudoc, Wageningen, The Netherlands.

Stroosnijder, L., and P. Koorevaar. 1972. Air pressure within soil aggregates during quick wetting and subsequent "explosion": 1. Preliminary experimental results. Meded. Fac. Landbouwwet. Rijksuniv. Gent 37: 1095-1106.

Wilsdon, B. H. 1921. Studies in soil moisture, part I. Memoirs of the department of agriculture in India. Chemical Series 6: 155-186.

Wit, C. T., de, and J. Goudriaan. 1978. Simulation of ecological processes. Pudoc, Wageningen, The Netherlands.

Wit, C. T., de, and H. van Keulen. 1975. Simulation of transport processes in soils. Pudoc, Wageningen, The Netherlands. 